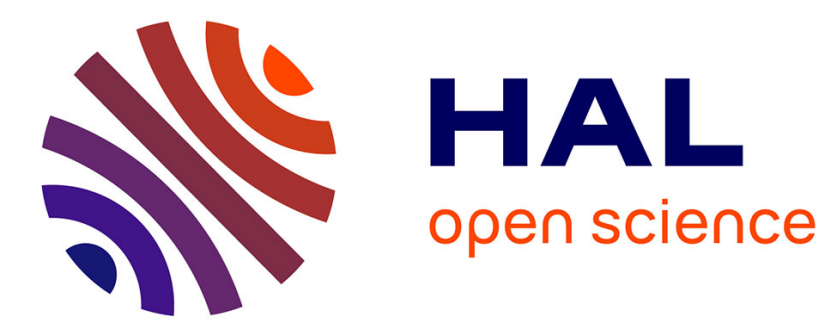

\title{
Evidences for liquid encapsulation in PMMA ultra-thin film grown by liquid injection Photo-CVD
}

\author{
Claudiu Constantin Manole, Olivier Marsan, Cedric Charvillat, Ioana
}

Demetrescu, Francis Maury

\section{- To cite this version:}

Claudiu Constantin Manole, Olivier Marsan, Cedric Charvillat, Ioana Demetrescu, Francis Maury. Evidences for liquid encapsulation in PMMA ultra-thin film grown by liquid injection Photo-CVD. Progress in Organic Coatings, 2013, vol. 76 ( $\left.\mathrm{n}^{\circ} 12\right)$, pp. 1846-1850. 10.1016/j.porgcoat.2013.05.027 . hal-01218622

\section{HAL Id: hal-01218622 \\ https://hal.science/hal-01218622}

Submitted on 21 Oct 2015

HAL is a multi-disciplinary open access archive for the deposit and dissemination of scientific research documents, whether they are published or not. The documents may come from teaching and research institutions in France or abroad, or from public or private research centers.
L'archive ouverte pluridisciplinaire HAL, est destinée au dépôt et à la diffusion de documents scientifiques de niveau recherche, publiés ou non, émanant des établissements d'enseignement et de recherche français ou étrangers, des laboratoires publics ou privés. 


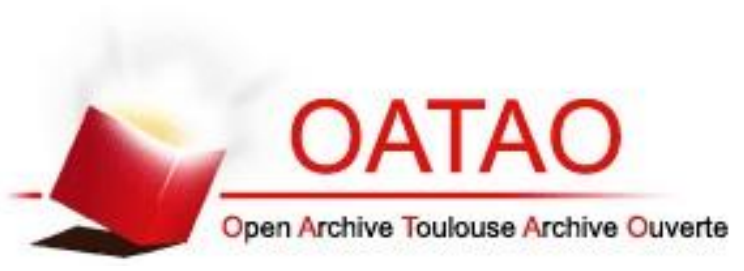

\section{Open Archive Toulouse Archive Ouverte (OATAO)}

OATAO is an open access repository that collects the work of Toulouse researchers and makes it freely available over the web where possible.

This is an author-deposited version published in: http://oatao.univ-toulouse.fr/ Eprints ID: 14102

To link to this article : DOI:10.1016/j.porgcoat.2013.05.027

URL : http://dx.doi.org/10.1016/j.porgcoat.2013.05.027

\section{To cite this version:}

Manole, Claudiu Constantin and Marsan, Olivier and Charvillat, Cedric and Demetrescu, Ioana and Maury, Francis Evidences for liquid encapsulation in PMMA ultra-thin film grown by liquid injection Photo-CVD. (2013) Progress in Organic Coatings, vol. 76 ( ${ }^{\circ}$ 12). pp. 1846-1850. ISSN 0300-9440

Any correspondence concerning this service should be sent to the repository administrator: staff-oatao@ listes.diff.inp-toulouse.fr 


\title{
Evidences for liquid encapsulation in PMMA ultra-thin film grown by liquid injection Photo-CVD
}

\author{
Claudiu Constantin Manole ${ }^{\mathrm{a}, \mathrm{b}, *}$, Olivier Marsan $^{\mathrm{a}}$, Cedric Charvillat $^{\mathrm{a}}$, Ioana Demetrescu ${ }^{\mathrm{b}}$, \\ Francis Maury ${ }^{\mathrm{a}}$ \\ a CIRIMAT, CNRS/INPT/UPS, 4 allée E. Monso, BP 44362, 31030 Toulouse cedex 4, France \\ b UPB, Faculty of Applied Chemistry and Materials Science, 1-7 Polizu 011061, Bucharest, Romania
}

Keywords:

Poly(methyl methacrylate)

Photo-CVD

Direct Liquid Injection

Raman Confocal Spectroscopy

Atomic Force Spectroscopy

\begin{abstract}
A B S T R A C T
This paper deals with the characterization of ultra-thin films of PMMA grown by an original photoassisted Chemical Vapor Deposition process equipped with a pulsed liquid injection system to deliver the monomer. The nanometric thick films showed a good ability to encapsulate a liquid phase as microdroplets protected by a thin polymeric tight membrane in the form of blisters. Techniques that are capable to analyze these heterogeneous structures at micro- and nanoscopic scale such as Raman Confocal Spectroscopy and Atomic Force Microscopy were used to characterize these polymer films. The liquid droplets were found to be monomer encapsulated by a PMMA film. The specific properties of these ultra-thin films exhibit self-healing capabilities at microscopic scale making them attractive for functionalization of surfaces and interfaces.
\end{abstract}

\section{Introduction}

The Chemical Vapor Deposition (CVD) is a valuable and versatile technique to grow micro- and nanostructured materials. It finds applications in many nanofabrication areas for instance to produce carbon nanotubes [1], low $\kappa$ dielectrics [2], core-shell nanostructures [3] and nanocomposite coatings [4]. To develop industrial CVD processes several technologies compete to deliver the high flow rates of reactive gas required for high growth rates and large scale reactors. Starting from liquid molecular compounds as precursors, this includes for instance Aerosol Assisted CVD [5] and pulsed Direct Liquid Injection CVD coupled to a flash vaporization of the liquid monomer to form the vapor phase (DLI-CVD) [6]. For this last technique a wide area of applications is targeted by intensive research on inorganic materials, either oxides [7-9] or carbides $[6,10,11]$. Organic materials are also deposited by CVD processes using various activation techniques of the reactive gas phase to compensate the very low deposition temperature imposed by these thermally fragile materials. Thus polymeric thin films were grown by initiated CVD (iCVD), e.g. hot-filament activation [12,13], Plasma Enhanced CVD (PECVD) [14] and the Graham process [15] using respectively chemical, plasma and thermal activation methods.

* Corresponding author at: Faculty of Applied Chemistry and Materials Science, University Politehnica Bucharest, Str. Polizu 1-7, 011061, sector 6, Bucharest, Romania. Tel.: +4021 40239 30; fax: +4021311 1796 .

E-mail address: claudiu.manole@ymail.com (C.C. Manole).
The ultra-thin polymeric films discussed in this paper were obtained by an original CVD process. First, the originality comes from the photon activation of the gas phase (Photo-CVD) without irradiating the thin layer growing on the substrate. Up to now this technique was reported to deposit inorganic materials [16]. Secondly, since the polymerization involves a liquid monomer as CVD precursor a novel approach was to use DLI-CVD. This dual innovation resulted in the deposition of ultra-thin (nanometric) poly (methyl methacrylate) (PMMA) films that, under particular conditions, encapsulated a liquid phase of its monomer. PMMA thin films were previously deposited by iCVD and evidences for a free-radical mechanism were found [13]. The approach of the DLI Photo-CVD process is based on the photon activation of the gas phase. It has the advantage of depositing at room temperature (or lower), without direct substrate irradiation and it allows to obtain a conformal coverage at low pressures (over solid and liquid surfaces).

Because the films are nanometric thick their characterization requires specific tools and methodologies. This paper gives an insight into the means of characterizing such polymeric ultra-thin films. The experimental results deduced from the techniques used give direct and indirect evidences of the main features of these PMMA thin films.

\section{Materials and methods}

The core of the Photo-CVD system stands in a vertical alignment perpendicular to the substrate surface of an Injection System, a Vaporization Chamber, an UV activation chamber of the gas phase 
Table 1

Experimental parameters used for DLI Photo-CVD of PMMA films.

\begin{tabular}{lll}
\hline Parameters & Inj-1 & Inj-2 \\
\hline $\begin{array}{l}\text { Deposition temperature }\left({ }^{\circ} \mathrm{C}\right) \\
\text { Total pressure (Torr) }\end{array}$ & 18 & 18 \\
Injector conditions & 9.5 & 9.5 \\
$f_{\text {liq }}(\mathrm{Hz})$ & 1 & \\
$t_{\text {on }}(\mathrm{ms})$ & 1 & 1 \\
$\mathrm{~N}_{2}$ carrier gas in injector $(\mathrm{sccm})$ & $\mathrm{N} / \mathrm{A}$ & 1 \\
$\mathrm{~N}_{2}$ carrier gas in vaporization chamber $(\mathrm{sccm})$ & 108 & $\mathrm{~N} / \mathrm{A}$ \\
Setpoint $(\%)$ & $\mathrm{N} / \mathrm{A}$ & 10 \\
$f_{\text {gas }}(\mathrm{Hz})$ & $\mathrm{N} / \mathrm{A}$ & 1 \\
\hline
\end{tabular}

and a Sample Reactor. The injector systems flash vaporizes the liquid monomer used as precursor. For the experiments reported in this paper, two commercial injection systems provided by Kemstream (www.kemstream.com) were used.

In the case of injection system 1 (Inj-1) a liquid injector communicates directly to a vaporization chamber. The amount of liquid injected is computer controlled by an opening time $\left(t_{\mathrm{on}}\right)$ and a repeating frequency $\left(f_{\text {liq }}\right)$ of the process. In the vaporization chamber the spray of the liquid is vaporized and mixed with a continuous stream of $\mathrm{N}_{2}$ used as carrier gas monitored by a mass flow meter.

The injector system $2(I n j-2)$ is a new generation designed to improve the atomization and the gas flow rate of the precursor. It has two-stage components. It contains a first liquid injector that pulses the monomer to a mixing chamber. The amount of liquid injected at this first stage is controlled by an opening time $\left(t_{\text {on }}\right)$ and a repeating frequency $\left(f_{\text {liq }}\right)$ of the process. This first liquid injector communicates with a second gas injector acting also as mixing chamber with the carrier gas. The gas injector mixes the spray with $\mathrm{N}_{2}$ as carrier gas and then pulses the liquid/carrier gas mixture into the flash vaporization chamber. The gas injection is monitored by a mass flow meter. The amount of gas injected is controlled by the software that converts a given setpoint (percent of $\mathrm{sccm}$ ) in opening time. The recurring pulsed opening time of the gas injector is given by a gas frequency $\left(f_{\text {gas }}\right)$. Both injection systems produce sprays with different characteristics in terms of average size of droplets and size distribution.

For Inj-1 setup, the monomer was pushed by a pressure of 3.8 bar of $\mathrm{N}_{2}$ towards the injector which operated at $f_{\text {liq }}=1 \mathrm{~Hz}$ and $t_{\mathrm{on}}=1 \mathrm{~ms}$. In the Inj-2 setup, the monomer was pushed with a pressure of 3.5 bar and the $\mathrm{N}_{2}$ carrier gas pressure was of 2 bar, with Setpoint $=10 \%$ and $f_{\text {gas }}=1 \mathrm{~Hz}$. The experimental parameters with respect to the injecting conditions are summarized in Table 1.

The UV chamber consists of four Hg low pressure lamps emitting at $254 \mathrm{~nm}$ (Heraeus model NNI 60/35 XL). For each lamp, the radiative flux at $254 \mathrm{~nm}$ in air at room temperature was $20 \mathrm{~W}$ and the irradiance at this wavelength was $150 \mu \mathrm{W} / \mathrm{cm}^{2}$ at a distance of $1 \mathrm{~m}$. They are $38 \mathrm{~cm}$ long and placed around a quartz tube of $5 \mathrm{~cm}$ in diameter and $40 \mathrm{~cm}$ long. The lamps and the tube are surrounded by a shell and a polished aluminum reflector. The temperature of the lamps and the quartz tube are maintained around $80^{\circ} \mathrm{C}$ by a stream of compressed air. The vapor phase is photo-activated when passing into this quartz tube and is carried towards the sample reactor. For the deposition, the monomer methyl methacrylate (MMA) (containing $\sim 0.004 \%$ hydroquinone as stabilizer) was mixed with $2 \%$ 1-hydroxycyclohexyl phenyl ketone as photo-initiator (PI) in order to aid the polymerization. They were both purchased from Sigma Aldrich and used as received.

The substrates in the growth reactor were placed perpendicularly to the main gas stream on a sample holder equipped with a temperature control system. They were kept at ambient temperature $\left(18^{\circ} \mathrm{C}\right)$. They were degreased and cleaned in ultrasonic bath with acetone and then ethanol. During deposition, a substrate area was masked in order to allow a direct comparison between a deposited and an undeposited zone. The masking was performed by placing the polished face of a $\mathrm{Si}(100)$ chip $(10 \mathrm{~mm} \times 5 \mathrm{~mm} \times 0.4 \mathrm{~mm}$ directly on the polished surface of a rectangular $\mathrm{Si}(100)$ wafer $(30 \mathrm{~mm} \times 5 \mathrm{~mm} \times 0.4 \mathrm{~mm})$. The intimate contact between the two polished surfaces prevents the diffusion of reactive gas between them and therefore the contamination of the masked surface of the substrate during the CVD run. In order to have a different type of surfaces, a $25 \mathrm{~mm} \times 25 \mathrm{~mm} \times 1 \mathrm{~mm}$ glass substrate was also used near the $\mathrm{Si}(100)$ substrate.

The Atomic Force Microscopy (AFM) data was obtained by an Agilent Technology 5500 AFM operating in acoustic mode with silicon Type VII MAC Lever from Agilent. The AFM measurements were made at a speed of $5 \mathrm{~nm} / \mathrm{s}$ at room temperature in ambient air. The Raman spectra and in situ Optical Micrographies were obtained at room temperature by a Horiba LabRAM Raman Confocal Spectrometer with a $5 \mathrm{~mW}$ laser emitting at $532 \mathrm{~nm}$. Both techniques offer direct characterization of the samples. However, with respect to ultra-thin nanometric layers, these characterizations can provide direct and indirect experimental results. The AFM offers direct results over the ultra-thin film due to the atomic force interactions that it measures; it is really a surface analysis technique.

The Raman Confocal Microscopy (RCM) analysis of ultra-thin polymeric films provides both direct and indirect results in the sense that it is not really a surface analysis technique and it can be invasive for the material analyzed. The samples can be analyzed as-deposited and after subsequent treatments either in situ during the Raman analysis as a result of the interaction between the laser beam and the material, or various post-treatments. In this work, we focus on post-thermal treatment in the ambient air of a Memmert Model 550 oven at $115^{\circ} \mathrm{C}$.

\section{Results and discussion}

The two DLI systems allowed encapsulating different volumes of liquid inside a polymeric thin membrane on the surface of a substrate. The two injection systems with continuous (Inj-1) or pulsed (Inj-2) carrier gas offered the possibility to investigate ultra-thin films with different morphologies and properties.

In a first series of deposition experiments, the $I n j-1$ injection system was used to obtain very thin polymeric film by the DLI Photo-CVD process. The formation of a nanometric thick membrane is difficult to identify and characterize, in particular to determine its thickness and structural features because organic polymers are generally nonconductive and thermally fragile materials. Information with respect to the presence of an ultra-thin film can be obtained directly by AFM or indirectly by extrapolating RCM data.

The AFM topography of an uncoated area (Fig. 1a) and a coated area (Fig. 1b) over the same substrate is shown in Fig. 1. It can be observed that the maximum height for a coated area increased by approximately $30 \mathrm{~nm}$ with respect to the uncoated one, which reveals the presence of an ultra-thin film covering the surface of the substrate. By mapping the phase of the cantilever oscillations, the AFM offers the possibility to identify variations in the sample composition. In Fig. 1c, the phase imaging of the coated area shows such a phase change and reveals two types of structures. First, what can be regarded as encapsulated liquid droplets (structure \#1), looking as blisters ca. $1 \mu \mathrm{m}$ in diameter spread out over the surface of the sample and, secondly, smaller heterostructures looking as a good conformal coverage of solid nanoparticles that contaminated the surface of the Si substrate by a thin film.

After the deposition, the blisters observed on the surface preserve their shape, size and distribution on the surface even after 2 months in ambient air and in dark. They do not show any change due to either chemical reactivity for instance with air or to evaporation of the volatile liquid. Indeed, if the liquid was the MMA 


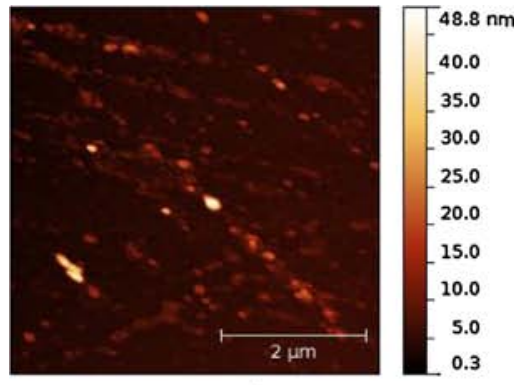

a)

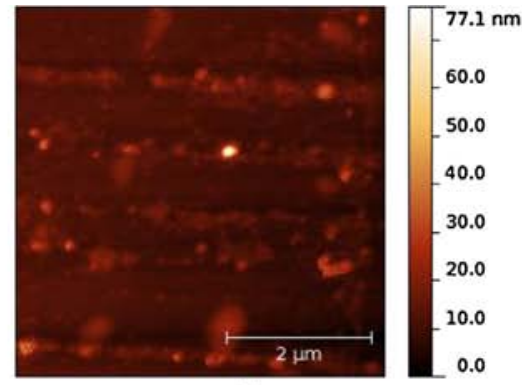

b)

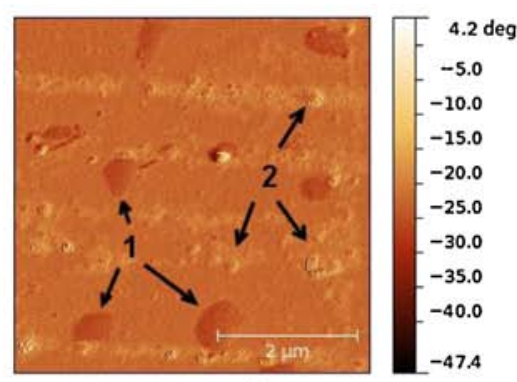

c)

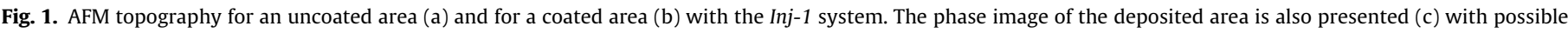
liquid encapsulation as blisters ( 1 ) and inhomogeneities resulting from conformal coverage of particles contaminating the surface of the Si( 100$)$ substrate ( 2 ).

monomer, its vapor pressure is sufficiently high $\left(29.5\right.$ Torr at $\left.20^{\circ} \mathrm{C}\right)$ to be completely evaporated. This indicates the liquid droplets are protected from the environment by a very thin polymeric membrane. At this stage, the best assumption is to consider that these blisters like structures contain a liquid that should be the monomer and the photoinitiator molecule since they are the sole liquid compounds involved in the CVD process.

Raman analysis of an as-deposited droplet-like structure approximately $10 \mu \mathrm{m}$ wide, reveals the $\mathrm{C}=\mathrm{C}$ bonds of both the monomer (not present in the polymer) and the photoinitiator with bands at $1640 \mathrm{~cm}^{-1}$ and $1660 \mathrm{~cm}^{-1}$, respectively. This results in a broad cumulative $C=C$ peak in this spectral range (Fig. 2). Even if there were only $2 \%$ of PI in the initial solution injected, it can be present in an amount significantly greater in these blisters. Indeed, the volatility of MMA (29.5 Torr at $20^{\circ} \mathrm{C}$ ) compared to PI $\left(2.2 \times 10^{-3}\right.$ Torr $)$ suggests that a part of the monomer is likely evaporated during the deposition under reduced pressure (9.5 Torr), which enriches the proportion of PI in the liquid condensed on the substrate surface.

The issue of separating the two species to determine the composition of the liquid in the droplets will be resolved by a subsequent post-treatment of the sample. The Raman technique was reported as a tool for estimating the extent of polymerization of PMMA after a thermal treatment, highlighting the $115^{\circ} \mathrm{C}$ temperature as optimum temperature for monomer polymerization [17]. As observed in Fig. 2, the band associated to the monomer decreases gradually with the increase of the time of a thermal post-treatment at $115^{\circ} \mathrm{C}$ in air. This indicates the presence of liquid MMA into the observed drop-like structure that progressively polymerize by

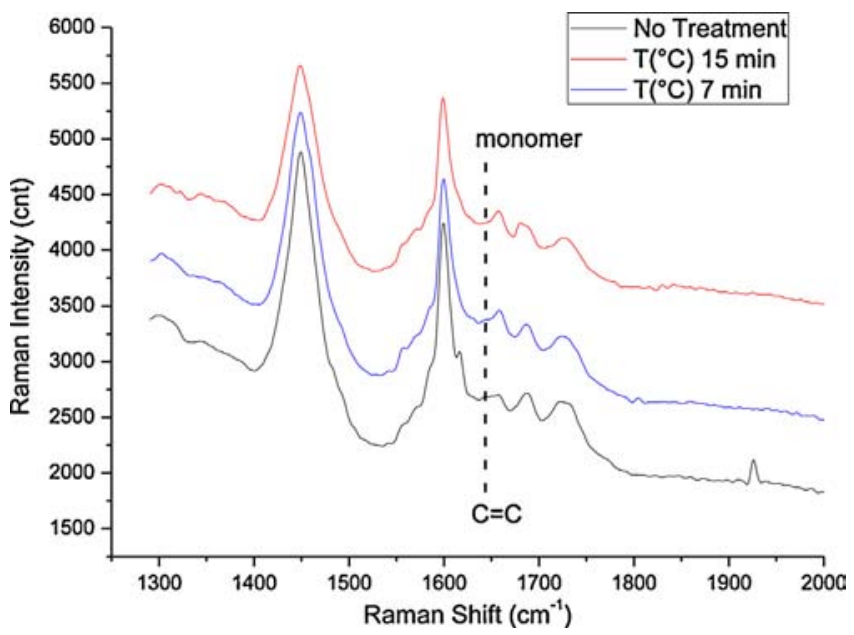

Fig. 2. Raman spectra of a $10 \mu \mathrm{m}$ encapsulated droplets obtained with Inj-1 system after an thermal $\left(115^{\circ} \mathrm{C}\right)$ post-treatment. thermal activation. During and after all of the Raman measurements, the film and the droplets deposited using the Inj-1 system were preserved intact.

The further use of the Inj-2 injection system will provide polymeric thin films with similar features, but with different properties. Larger droplets were incorporated into a thin film grown using the Inj-2 injection system. The AFM force microscopy was performed onto three points indicated in the AFM topographical image (Fig. 3). The Atomic Force Spectroscopy involves three steps of the AFM cantilever behavior: $(i)$ an approach half cycle, when the cantilever tip approaches the surface, (ii) a contact with the sample and (iii) a retracting half cycle when the cantilever retracts. Fig. 3b shows that the bare Si substrate (the reference) has a short approach/retracting cycle $(\sim 0.5 \mathrm{~s})$. Due to the ultra-thin polymeric film covering the substrate, the approach/retract cycles are longer $(\sim 1.5 \mathrm{~s})$ that indicates a more elastic behavior compared to the bare Si substrate. If pure liquid were present onto the surface as free droplets, i.e. without encapsulation in an ultra-thin membrane as blisters, the AFM tip would have penetrated the liquid easily, indicating thus a different retracting cycle for the region 3 compared to regions 1 and 2 .

It is well known that the focused Raman laser generates heat that can damage materials if they absorb the photons. For instance, the laser-induced thermal effects were studied on carbon nanotubes and on magnetite oxidation [18,19]. Also, the optimized laser energy can be used to achieve welding of PMMA sheets [20]. Here, during the Raman Microscopy analyses of layers obtained by Inj2 system, the ultra-thin film on the Si substrate was irradiated in situ by the laser beam. During this laser irradiation for approximately $15 \mathrm{~s}$, both a destructive and a constructive effect can be extrapolated.

Firstly, the as-deposited blister approximately $30 \mu \mathrm{m}$ in diameter (Fig. 4a) on which the laser focus shows a catastrophic failure of the film by the presence of a crater-like structure (Fig. 4b). The focal diameter of the RCM laser was $430 \mathrm{~nm}$. The resulting crater-like geometry after the exposure to laser beam reaches approximately $5 \mu \mathrm{m}$ in diameter. The degradation process can be essentially described by the following steps: ( $i$ ) laser energy absorption at the thin film interface with the Si substrate leading to a sudden temperature increase originating essentially from absorption of the $\mathrm{Si}$, (ii) initial thermal strain and possibly melting (such as depolymerization of PMMA [21]) and/or vaporization of the liquid species (MMA), and (iii) thermally induced polymerization from encapsulated monomer in the low temperature areas (at the edges of the crater) [22]. In Fig. 4a and b, the laser beam was focused on a heterogeneity embedded in the blister. This heterogeneity likely originating from the surface contamination of the Si substrate is uncovered after laser irradiation at the center of the crater as shown in Fig. 4b. For blisters without such contamination the bottom of the crater is clean after laser exposure and no particle is observed at the center (Fig. 4d). 

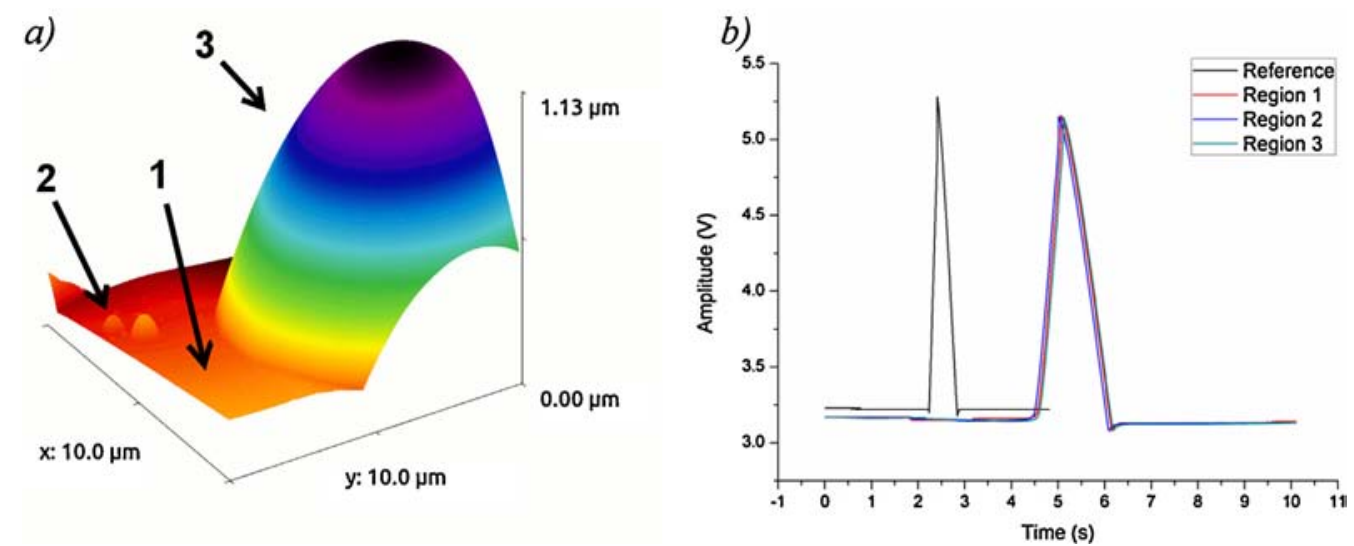

Fig. 3. The AFM topography (a) with arrows indicating the areas where the force spectroscopy data (b) were obtained for the PMMA film polymerized with the Inj-2 system and for the bare Si substrate.
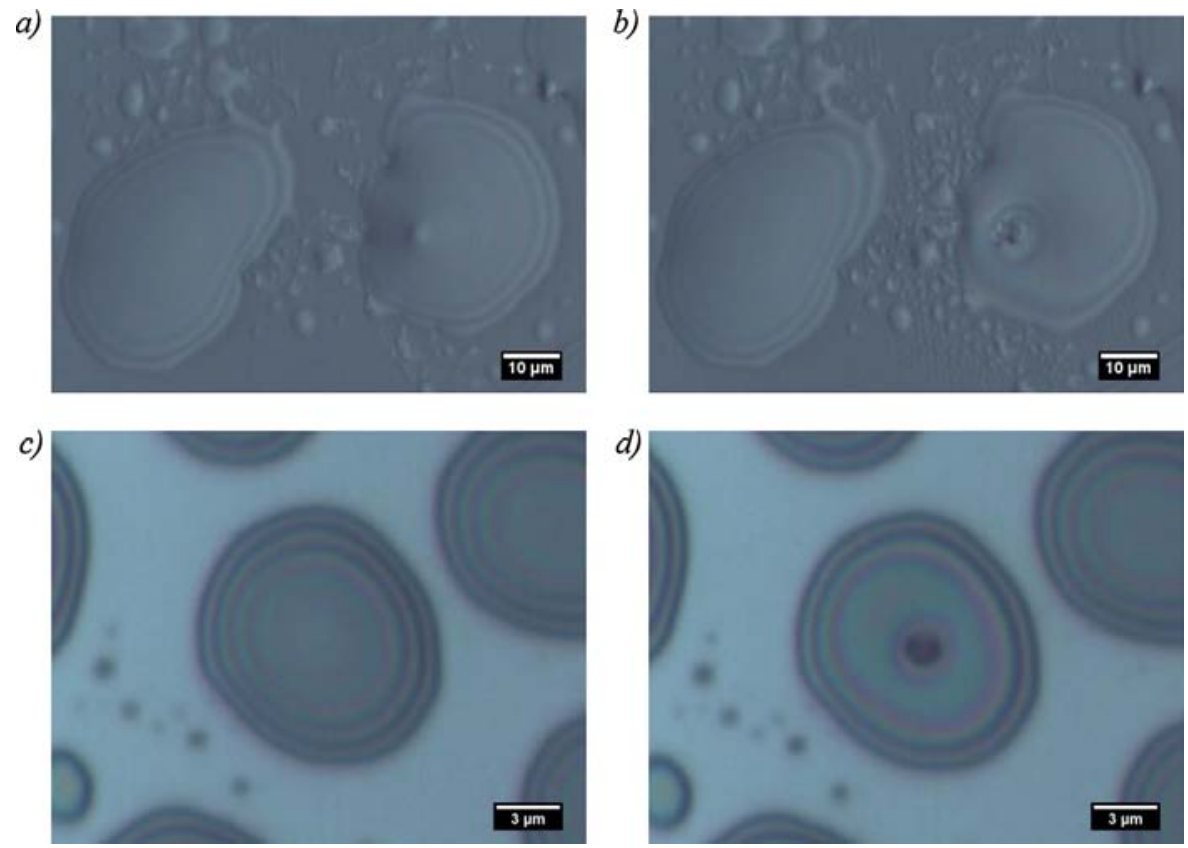

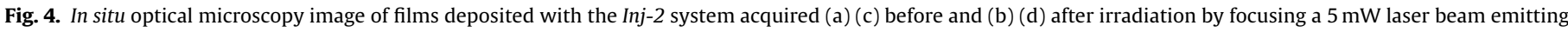
at a wavelength of $532 \mathrm{~nm}$ of two blister-like structure deposited over (a) (b) glass and (c) (d) $\operatorname{Si}(100)$ substrates during Raman analysis.

The presence of such crater-like structures after several Raman analyses supports this degradation process. Raman laser provides a heat gradient across the surface of the sample, with a maximum temperature at the center of the spot and a sharp decrease towards ambient temperature at the periphery. Shebanova and Lazor observed that Raman laser irradiation (at $512 \mathrm{~nm}$ ) induced the oxidation of magnetite [18]. This oxidation could occur at temperatures close to $240^{\circ} \mathrm{C}$ [18]. Their study was oriented towards the determination of the local temperature for the laser-heated spot. It involved the variation of the power to the sample $(7-60 \mathrm{~mW})$ over a spot size of around $5-10 \mu \mathrm{m}$, for instance $50 \mathrm{~mW} / 5 \mu \mathrm{m}$. For the optical objective used in our experiments the calculated spot size of our $5 \mathrm{~mW}$ laser is around $0.5 \mu \mathrm{m}$. Therefore the approximate power per surface area of the RCM used in our experiments is of the same order of magnitude $(5 \mathrm{~mW} / 0.5 \mu \mathrm{m})$. At $50 \mathrm{~mW}$ the temperature was correlated by Shebanova and Lazor at around $410^{\circ} \mathrm{C}$ for magnetite [18]. Si substrate strongly absorbs irradiation at $532 \mathrm{~nm}$ and it can readily transmit its local heat to the polymeric film. Therefore, it can be suspected that at the observed radius of $2.5 \mu \mathrm{m}$ from the center of the crater (i.e. edge of the crater) the temperature could reach an optimum value near $100^{\circ} \mathrm{C}$ that leads to a self-healing mechanism of the blister by thermal polymerization. The sealing at the edge of the exposed area can be considered as a constructive effect of laser irradiation (Fig. 4c).

The different behavior of the samples prepared using the Inj-1 and Inj-2 systems observed during Raman analyses may be due to a different composition of the liquid (for instance the ratio MMA/PI) encapsulated in the polymer film. The nanometer-thick PMMA films that encapsulate polymerizable monomeric species show self-healing properties, with the ability to re-seal the area that suffered a catastrophic failure. This is achieved under particular conditions dictated by the activation parameters of the polymerization such as the temperature induced by laser heating.

\section{Conclusions}

An original Photo-CVD process was used to obtain ultra-thin nanometric PMMA films. After the photo-excitation of the gas phase, the monomer polymerizes over both liquid and solid 
surfaces. Two commercial injector systems allowed liquid encapsulation as blisters with different morphologies and properties. A part of the liquid monomer was encapsulated as microdroplets in the ultra-thin polymeric film. AFM and RCM techniques were used to characterize such films and evidences for liquid encapsulation were given. The film presents self-healing behavior at micrometric scale, a property that has the potential to be also exploited at larger scales.

\section{Acknowledgements}

The work has been funded by the Sectoral Operational Programme Human Resources Development 2007-2013 of the Romanian Ministry of Labour, Family and Social Protection through the Financial Agreement POSDRU/88/1.5/S/61178.

\section{References}

[1] R.K. Sahoo, V. Daramalla, C. Jacob, Mater. Sci. Eng. B 177 (2012) 79-85.

[2] S.-J. Cho, I.-S. Bae, J.-H. Boo, Thin Solid Films 518 (2010) 6417-6421.

3] L. Cao, H. Jiang, H. Song, Z. Li, G. Miao, J. Alloys Compd. 489 (2010) 562-565.

[4] D. Barreca, D. Bekermann, E. Comini, A. Devi, R.A. Fischer, A. Gasparotto, M. Gavagnin, C. Maccato, C. Sada, G. Sberveglieri, E. Tondello, Sens. Actuators B: Chem. 160 (2011) 79-86.
[5] F.-D. Duminica, F. Maury, S. Abisset, Thin Solid Films 515 (2007) 7732-7739.

[6] A. Douard, C. Bernard, F. Maury, Surf. Coat. Technol. 203 (2008) 516-520.

[7] M.E.A. Warwick, C.W. Dunnill, J. Goodall, J.a. Darr, R. Binions, Thin Solid Films 519 (2011) 5942-5948.

[8] M.G. Nolan, J.A. Hamilton, S. O’Brien, G. Bruno, L. Pereira, E. Fortunato, R. Martins, I.M. Povey, M.E. Pemble, J. Photochem. Photobiol. A: Chem. 219 (2011) $10-15$

[9] A. Douard, F. Maury, Surf. Coat. Technol. 200 (2006) 6267-6271.

[10] A. Shanaghi, A.R.S. Rouhaghdam, S. Ahangarani, P.K. Chu, T.S. Farahani, J. NonCryst. Solids 258 (2012) 3051-3057.

[11] N. Yoshida, S. Terazawa, K. Hayashi, T. Hamaguchi, H. Natsuhara, S. Nonomura, J. Non-Cryst. Solids (2012), http://dx.doi.org/10.1016/j.jnoncrysol.2012.03.028.

[12] K. Chan, K.K. Gleason, Langmuir 21 (2005) 11773-11779.

[13] K. Chan, K.K. Gleason, Chem. Vap. Deposit. 11 (2005) 437-443.

[14] T.B. Casserly, K.K. Gleason, Chem. Vap. Deposit. 12 (2006) 59-66.

[15] V. Santucci, F. Maury, F. Senocq, Thin Solid Films 518 (2010) 1675-1681.

[16] A.M. Boies, J.T. Roberts, S.L. Girshick, B. Zhang, T. Nakamura, A. Mochizuki, Nanotechnology 20 (2009) 295604.

[17] F. Pallikari, G. Chondrokoukis, M. Rebelakis, Y. Kotsalas, Mater. Res. Innov. 4 (2001) 89-92.

[18] O.N. Shebanova, P. Lazor, J. Raman Spectrosc. 34 (2003) 845-852.

[19] Y. Zhang, H. Son, J. Zhang, J. Kong, Z. Liu, J. Phys. Chem. C 111 (2007) 1988-1992.

[20] I. Jones, J. Rudlin, Proceedings of the 2nd International Conference on Joining Plastics, National Physical Laboratory, 2006, pp. 25-26.

[21] B.B. Troitskii, G.A. Domrachev, L.V. Khokhlova, L.I. Anikina, Doklady Phys. Chem. 375 (2000) $268-270$.

[22] J. Bovatsek, A. Tamhankar, R. Patel, N.M. Bulgakova, J. Bonse, Proc. SPIE 7201 (2009) 720116. 